\title{
Recent Progress in the Chemistry of the Sex Hormones
}

\author{
By Dr. J. W. Cook
}

$\mathrm{T}$ HE conversion of cholesterol into the male sex hormone (androsterone) ${ }^{2}$, already noted in these columns ${ }^{2}$, with its attendant elucidation of the complete chemical structure of this hormone, provides a convenient point at which to review the present state of chemical knowledge of the sex hormones.

Stimulated by secretions of the anterior lobe of the pituitary, the gonads (testis, ovary) secrete substances which control the growth and development of the organs of reproduction, and excite the secondary sexual characteristics. There are many biological tests with castrated male mammals, birds and fishes by which the presence of such substances in testicular extracts may be recognised, as has long been known. Similar active extracts may be prepared from the urine of males, and in 1931 Butenandt and Tscherning ${ }^{3}$ isolated four crystalline substances from oily extracts prepared from 100,000 litres of such urine. One of these, when injected in minute doses, produced growth of the undeveloped comb of the capon. The measurement of the extent of such growth, resulting from injections made under exactly defined conditions, gives a quantitative test for the male hormone ${ }^{4}$, and is the only biological test which had hitherto been applied to the pure crystalline active substance (now known as androsterone). Thus it has not been possible to ascertain if the manifold effects of testicular extracts on male organs are due to one or to several substances. Now that Ruzicka ${ }^{1}$ has achieved the artificial preparation of androsterone, it will be available in sufficient quantity to make a complete biological study of its effects, and such questions will doubtless soon be answered. Indeed, it is reported already that the artificial hormone had very definite regenerative action on the accessory male organs (seminal vesicles, prostate and penis) of castrated male rats.

The immense difficulty of isolation of appreciable amounts of androsterone from urine, due not only to the very small concentration, but also to the presence of chemically related inactive substances, has precluded any attempt to study the molecular structure by means of degradative reactions. Nevertheless, Butenandt was able to characterise the substance as a saturated hydroxyketone of the probable formula $\mathrm{C}_{19} \mathrm{H}_{30} \mathrm{O}_{2}$, and to prepare a number of functional derivatives such as the oxime, acetate, etc. On the assumption of a relationship to the sterols and to ostrin, the structure (II) was suggested for androsterone. This structure has been completely verified by
Ruzicka's isolation of androsterone from the neutral products of the chromic acid oxidation of the acetate of epidihydrocholesterol (I) :-

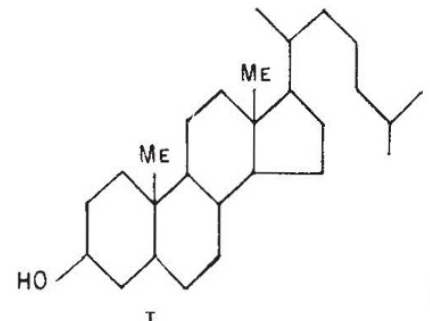

I

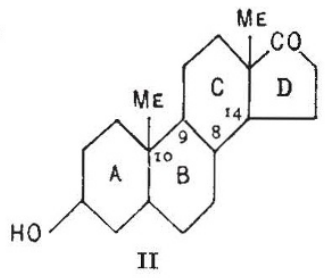

II
Of the 128 stereoisomerides of (II) which are theoretically possible, four were prepared by Ruzicka. The configurations of these are naturally those of the sterols from which they were formed by oxidation. These sterols were dihydrocholesterol, epidihydrocholesterol (both have trans configurations of rings $A$ and $B$, but differ in the spatial positions of the hydroxyl group), coprosterol and epicoprosterol (both of these have cis configurations of rings $A$ and $B$ ).*

The remarkably specific action of the hormone was shown by the fact that the two cis hydroxyketones (II) were without action on comb growth in doses about fifteen times as large as that of androsterone which sufficed for a 20 per cent increase in area of the comb. By contrast, it may be recalled that the biological activities of œestrin may be reproduced by a whole series of artificial compounds differing appreciably in structure from the natural hormone ${ }^{5}$.

Great interest attaches to the biogenetic implications of Ruzicka's experiments. The hypothesis that androsterone is an ultimate product of biological degradation of the side chain of cholesterol, passing through the intermediate phases of lithocholic acid and pregnandiol, is no longer tenable, for lithocholic acid and pregnandiol both belong to the coprostane (allocholestane) series, whereas androsterone is shown to be related stereochemically to epidihydrocholesterol. In this connexion, Ruzicka records in a footnote an experiment with lithocholic acid which shows that the bile acids belong to the epicoprosterol series. Ruzicka suggests that the biological conversion of cholesterol into androsterone proceeds through the same stages as the transformation in vitro, that is, reduction to dihydrocholesterol, epimerisation of

* The formulations used by Ruzicka to represent the configurations of these sterols and their derivatives are open to criticism on the ground that they assign definite configurations to rings $A$ and $C$ with respect to carbon atoms $\mathrm{C}_{9}$ and $\mathrm{C}_{10}$, and to rings $B$ and $D$ with respect to $\mathrm{C}_{8}$ and $\mathbf{C}_{\mathbf{1 4}}$. No information bearing on these questions is at present available. 
the hydroxyl group, and then oxidative fission of the side chain. It seems to the present writer that the dehydroandrosterone isolated from urine by Butenandt ${ }^{6}$ should be considered in this connexion. This is an unsaturated hydroxyketone which can be hydrogenated catalytically to androsterone. If the double bond of dehydroandrosterone is in the position suggested by Butenandt (III), then this substance rather than dihydrocholesterol may be the intermediate in the natural formation of androsterone. The fact that the configurations of rings $B, C$ and $D$ of androsterone are identical with those of the corresponding rings of the sterols and bile acids is a strong argument against the view that the hormone is synthesised by the body independently of cholesterol.

Dehydrogenation of $\operatorname{ring} A$ of androsterone, with loss of the methyl group at $\mathrm{C}_{10}$, would lead to structure (IV), which is the formula at present favoured for the principal œstrus-producing hormone, œstrone. Developments in the chemistry of this hormone are too well known to require more than a passing reference here ${ }^{7}$. The demonstration of the presence of the phenanthrene ring system ${ }^{8}$ and the proof that the complete ring system is that of cholesterol with the hydroxyl group in the same position ${ }^{9}$ lend strong support to structure (IV) for œstrone, but it must be emphasised that experimental proof of the position of the carbonyl group is lacking, except that it is known to be in the five-membered ring. Also, nothing is known concerning the configuration of the ring system of cestrone (sixteen stereoisomerides of (IV) are theoretically possible).

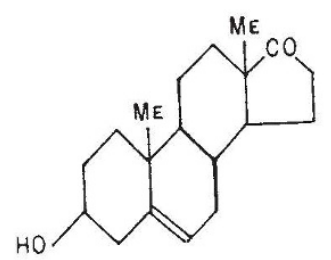

III

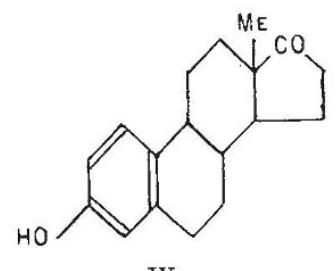

IV
Together with its other physiological effects, œstrin is responsible for the œstrous phenomena of the lower mammals, and probably also for the reparative changes of the uterine endometrium during the first half of the post-menstrual period in primates. Closely bound up with œstrin in its action is the hormone secreted by the corpus luteum, an organ formed normally by development of the ruptured follicle after expulsion of the ovum. The corpus luteum hormone (also known as progestin) exerts a specific proliferative action on the uterine endometrium, and prepares the uterus for implantation of the fertilised ovum. Moreover, actively secreting corpora lutea (or suitable extracts) must be present during the phenomenon of pseudo-pregnancy which occurs in the lower animals (mouse, rat, rabbit, dog) ; in some species (for example, the rabbit, but not the primates) the presence of progestin is necessary for the maintenance of pregnancy. It is believed that œstrin and the corpus luteum hormone, acting in conjunction, are responsible for the menstrual cycle in the human species.
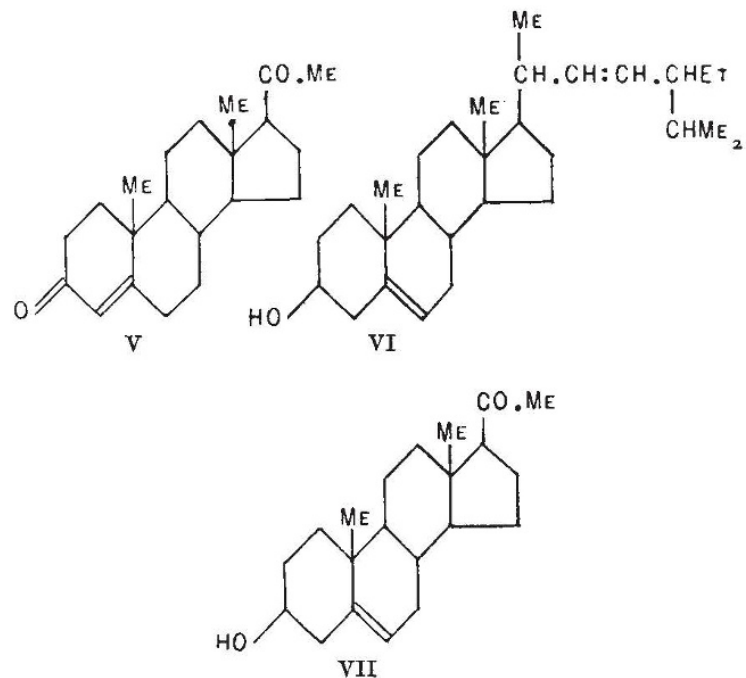

The pure corpus luteum hormone has recently been isolated from corpus luteum extracts by three groups of workers ${ }^{10,11,12}$. As with the male hormone, isolation of the active principle is complicated by the accompanying inactive substances of similar chemical nature, and there was at first some difference of opinion regarding the physical characteristics of the pure hormone. All three groups of workers. are now agreed that the principal hormone is an unsaturated diketone of m.p. $128^{\circ}$, and they havealso isolated a second substance of m.p. $118^{\circ}-120^{\circ}$, which Slotta and his collaborators find also to have the biological activity of the hormone. The second substance is converted by heat into the hormone, m.p. $128^{\circ}$, and the two active substances are regarded by Slotta as stereoisomerides (the suggested stereoisomeric forms are, in fact, identical if his postulated formula is correct). On the assumption that this hormone also is derived from the sterols, its composition and properties suggest that it is an unsaturated derivative of pregnandione, that is, of the diketone arising from the oxidation of pregnandiol, a physiologically inactive substance first isolated by Marrian ${ }^{13}$ from urine of pregnancy, and shown by Butenandt ${ }^{14}$ to belong to the cholane series. Slotta, Ruschig and Fels attribute structure (V) to the corpus luteum hormone, the position assigned to the double bond depending on spectroscopic evidence, which suggests an $\alpha \beta$-unsaturated ketone. Evidence in favour of this view is afforded by the 
degradation of the side chain of stigmasterol (VI)* to a substance having corpus luteum hormone activity ${ }^{15}$. Adopting the technique of Fernholz ${ }^{16}$, Butenandt and his collaborators converted stigmasterol into a hydroxy-bisnorcholenic acid (VI ; but with side chain degraded to - $\left.\mathrm{CHMe} \cdot \mathrm{CO}_{2} \mathrm{H}\right)$. By a further series of changes this acid was converted into the hydroxyketone (VII), which on mild oxidation gave a mixture of substances. The lowest melting fraction from the mixture (m.p. $129^{\circ}-135^{\circ}$ ) had corpus luteum hormone activity in doses only slightly greater than those required with the pure hormone. The report of the isolation of a chemically pure substance from this mixture will be awaited with interest. It may well be that

* It should be observed that the positions assigned to the hydroxyl group and the nuclear double bond of stigmasterol are based on analogy with cholesterol; there is no experimental justification for this ansumption. the day is not far distant when the three sex hormones (androsterone and progestin as well as œstrin) will be available for clinical use in chemically pure crystalline form.

${ }^{1}$ Ruzicka, Goldberg, Meyer, Brüngger and Eichenberger, Helv. Chim. Acta, $17,1389,1395 ; 1934$.

2 NAture, 134, 563, Oct. 13, 1934 . 3 Butenandt and Tscherning, $Z$. angew. Chem., $905 ; 1931$. A ing Ergebnisse der Physiologie, 35, 301 , 1933. See also reference (6). ' Schoeller and Gehrke, Wien. Arch. 5 Cook, Dodds, Hewett and Lawson. Proc. Roy. Soc. B ; 1931 . 1934.

Butenandt, Wien. Klin. Wochschr., 47, 936; 1934. Forschungen und Fortschritte, 10, 266, 276; 1934.

"A review, with bibliography, is given by Störmer and Westphal, Ergebnisse der Physiologie, 35, 318; 1933.

Butenandt, Weidlich and Thompson, Ber., 66, 601; 1933.

${ }_{10}$ Butenandt, Westphal and Hohlweg, Z. physiol. Chem., 227, 84 ; 1934.

11. Slotta, Ruschig and Fels, Ber., 67, 1270, 1624; 1934

12 Hartmann and Wettstein, Helv. Chim. Acta., 17, 878, $1365 ; 1934$.

13 Marrian, Biochem. J., 23, 1090; 1929.

${ }_{14}$ Butenandt, Ber., 63, 659; 1930. 64, 2529; 1931.

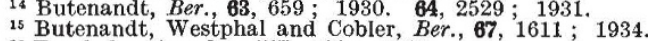

1s Fernholz, Annalen, 507, 128; 1933.

\section{Use and Origin of Yerba Maté*}

\section{By CAPT. T. A. JoYce, о.в.E.}

$\mathrm{T}^{\mathrm{H}}$ $\mathrm{HE}$ origin of the practice of infusing the leaves of the ilex is very obscure. The earliest mention of the drink I have quoted is from Nicholás Durán (1626-27). By that time, as the extract shows, the beverage had spread far and wide through South America. But there is no account of its discovery. Pinelo, writing in 1636, refers to an author, Robles Cornejo, where he says a full account of the herb is given. Cornejo's work, "Examen de los Simples Medicinales", dated 1617, must contain the first reference to the drink. But the book existed only in manuscript and, though mentioned in Cejador y Franca's "Historia de la Lengua y Literatura Castellaña", has absolutely disappeared.

So far, evidence would seem to show that the drink was a native discovery, developed by the Jesuits ; but a study of the early history of the country provides another aspect. The Rio de la Plata was discovered by Juan Diaz de Solis in $\mathbf{1 5 1 6 .}$ In 1534, an expedition was sent from Spain under Pedro de Mendoza to make permanent occupation of the country to the north. With him sailed Ulrich Schmidt, or Schmiedel, as he was called by the Spaniards, a Bavarian agent of merchants in Seville. He ascended the Paraná and Paraguay with the pioneer expeditions and made many journeys of exploration through the heart of the Guarani country, finally making a cross-country journey of some hundred and thirty miles from the upper Paraná to São Vicente; then he returned to Europe after an absence of nearly twenty years.

Schmidt's reminiscences are remarkable from several points of view, and perhaps especially for

* Continued from p. 724. the accuracy of his memory and the almost incredible vileness of his orthography in dealing with Spanish and Indian words. His narrative is of great importance to anthropology, because it is the report of a pioneer and an observer. Whatever he may have forgotten, his mind is extraordinarily clear on the food question. He writes in detail what he had to drink and eat and where, day by day. Naturally, food was very important, and these European expeditions, living on the country, were often on the verge of starvation. For days they had to pass through unoccupied country, and their minds were naturally focused on the food quest. Schmidt tells how the Carios make 'wine' of Mandepore (manioc) and of honey ; the Mbaia and Payagua, of 'fenugreek' ; the Guyacurú, of the algarroba bean. But in none of his copious food notes does he ever make mention in his twenty years' experience of the use of the ilex leaf either chewed or infused.

During the period of Schmidt's residence in Paraguay, Cabeza de Vaca was sent to the country as Adelantado. From São Francisco, in the far south of Brazil, where he landed, he made a remarkable overland journey to the newly founded settlement of Asunción, passing through the heart of the country where the ilex grew naturally. In the course of his three years' residence he made several journeys northward. His narrative (1555) is full of details of considerable ethnographical importance and, though he pays less attention to local foodstuffs than Schmidt, the precarious nature of his supplies led him to record much useful information on this subject. Yet in his account there is no mention of the ilex. 